\title{
Skin manifestations after bariatric surgery
}

Yada Itthipanichpong ', Wilawan Damkerngsuntorn' ${ }^{1}$ Natsinee Tangkijngamvong ${ }^{1}$, Suthep Udomsawaengsup ${ }^{2}$, Patchaya Boonchayaanant ${ }^{3}$, Chanat Kumtornrut', Stephen J. Kerr ${ }^{4}$, Pravit Asawanonda ${ }^{1}$ and Pawinee Rerknimitr ${ }^{1 *}$ (D)

\begin{abstract}
Background: Skin signs observed in morbid obesity may change as the weight reduces, especially post-bariatric surgery (BaS). Data concerning the skin findings exclusively in post-BaS patients remain limited.

Methods: Seventy post-BaS patients were examined for cutaneous abnormalities. The patients were divided into those with successful weight loss (\% excessive body weight loss (EBWL) of at least 50\%) and a non-successful group (\%EBWL <50\%).

Results: Forty-six patients with successful weight loss demonstrated a significantly lower prevalence of acanthosis nigricans on the neck, axillae and inguinal areas, keratosis pilaris (KP) and pebble fingers. However, a higher prevalence of alopecia was observed. After adjustment with patients' factors, KP (adjusted odds ratio (aOR) $=0.21,95 \% \mathrm{Cl} 0.06-0.74$, $p=0.02)$ and pebble fingers ( $\mathrm{aOR}=0.09,95 \% \mathrm{Cl} 0.01-0.89, p=0.04)$ remained significantly less likely in patients with successful weight loss. Laboratory results comparing pre- and post-surgery values revealed significant decreases in fasting plasma glucose, hemoglobin A1c, and triglyceride and an increase of high-density lipoproteins in both groups. However, significant decreases of liver aminotransferases (AST and ALT) were observed only in the successful group $(p=0.04,0.003)$. Nonetheless, a decrease in vitamin B12 $(p=0.01)$ was observed in the successful group.
\end{abstract}

Conclusion: Weight loss after BaS provided an improvement for metabolic profiles. Successful weight reduction resulted in better skin improvement. However, nutritional supplements may be necessary.

Trial registration: Thai Clinical Trials Registry TCTR20171003002. Registered October 3. 2017, retrospectively registered.

Keywords: Skin, Cutaneous sign, Obesity, Bariatric surgery, Weight loss

\section{Background}

Obesity represents one of the major health concerns on a global scale. Substantial increases in the prevalence of patients with obesity has raised the public awareness over decades. The prevalence of overweight individuals (body mass index (BMI) $\geq 25 \mathrm{~kg} / \mathrm{m}^{2}$ ) was reported to be as high as $40 \%$ of the total world population [1]. Obesity has various impacts on the skin, including changes in skin physiology, myriads of skin manifestations and aggravation of skin diseases.

\footnotetext{
* Correspondence: Pawinee.r@chula.ac.th

'Division of Dermatology, Department of Medicine, Faculty of Medicine, Skin and Allergy Research Unit, Chulalongkorn University, 1873 Rama IV Road, Pathumwan, Bangkok 10330, Thailand

Full list of author information is available at the end of the article
}

Skin signs associated with obesity may be divided into those that occur as a result of insulin resistance such as acanthosis nigricans (AN) [2-4] acrochordons [3, 4], and keratosis pilaris (KP) [3-5]. Additionally, mechanical effects may give rise to plantar hyperkeratosis, striae distensae, adiposis dolorosa, and chronic venous insufficiency $[3,4]$. Skin infections, i.e. candidiasis and the inflammatory skin disorders namely psoriasis and hidradenitis suppurativa are observed at higher frequency and severity in patients with obesity $[3,4,6]$. Finally, skin manifestations due to metabolic derangements such as gouty tophi are also seen $[3,4]$.

AN is characterized by symmetric velvety hyperpigmented plaques. The common locations are on the neck, axillae, inguinal, inframammary, and genital regions $[7$, 
8]. AN is reported to be found in as high as $74 \%$ in patients with obesity [9]. Acrochordons or skin tags are pedunculated soft brownish papules. They are commonly detected together with AN on the neck, axillae, and inguinal area [10]. KP is manifested as multiple small, perifollicular, spiny papules on the extensor aspect of the extremities. Pebble fingers, or Huntley's papules are classically described in association with diabetes mellitus (DM) type 2 in patients with obesity $[8,11]$. They usually present as asymptomatic grouped, multiple minute papules, which may coalesce into confluent plaques. Common locations are the dorsum of the hand, knuckles, and periungual areas. It is believed that pebble fingers represent a variation of diabetic thick skin [8].

Treatments and interventions to induce weight loss are of paramount importance, especially for patients with morbid obesity (BMI $\geq 40 \mathrm{~kg} / \mathrm{m}^{2}$ ) [12]. Bariatric surgery is one of the most effective long-term weight reduction therapies. Success of bariatric surgery is defined as whether at least 50\% excessive body weight loss (EBWL) is achieved [13]. Bariatric surgery may lead to $60-80 \%$ EBWL in the first year and stabilize at $50-60 \%$ in $80 \%$ of gastric bypass patients [14].

Moreover, successful bariatric surgery has demonstrated a wide range of health benefits, including the skin and overall medical conditions. Improvements of obesity-associated complications namely DM, hypertension, dyslipidemia, and obstructive sleep apnea have been documented [12, 14, 15]. In addition, bariatric surgery has both positive and negative impacts on the skin. There are reports of improvements in many skin conditions such as psoriasis [16, 17], intertrigo, hidradenitis suppurativa and ulcerated necrobiosis lipoidica diabeticorum [17, 18]. Conversely, the occurrence of adverse skin conditions, mostly involving nutritional deficiency, for example, of iron, folic acid, vitamin and trace elements, has been reported [17-20]. Furthermore, massive weight loss also contributes to skin laxity [21].

Nonetheless, information concerning the skin signs exclusively seen in post-bariatric surgery patients remain limited. To our knowledge, there is no study comparing the skin signs in those with successful versus nonsuccessful weight loss. Therefore, we conducted this cross-sectional study to investigate the skin signs, skin diseases, and laboratory values in post-bariatric surgery patients, in an attempt to shed some light in this area that may be beneficial for clinical practice and counseling patients.

\section{Methods}

\section{Study design and ethical consideration}

This cross-sectional study was conducted at King Chulalongkorn Memorial Hospital, Bangkok, Thailand from February to November 2017. The trial protocol was approved by the local Institutional Review Board, the approval number 633/60. The trial was registered with Thai Clinical Trials Registry, TCTR number 20171003002. Written informed consent was obtained from all participants. The present study adheres to CONSORT guidelines.

\section{Study subjects}

The inclusion criteria were as follows: patients aged more than 18 years, diagnosed with morbid obesity $\left(B M I \geq 40 \mathrm{~kg} / \mathrm{m}^{2}\right)$ who had undergone a bariatric surgery. Exclusion criteria were patients who were not willing to participate or have skin conditions treated 6 months prior to the examination.

\section{Study protocol}

Consecutive cases of post-bariatric surgery patients were interviewed and thoroughly examined for the presence of any skin abnormalities by certified dermatologists. The skin examination was conducted once in all patients at a post-surgical visit, therefore the skin findings were obtained only at one point in time. However, information regarding the types of bariatric surgery, clinical data and laboratory values (at baseline, immediately beforeand at 6 months, or later dates, where applicable after the surgery) were extracted from the medical records. The diagnosis of alopecia was based on the history of increase hair shedding and a thorough hair and scalp examination was then performed. The patients were categorized into two groups according to their weight loss status. The results of surgery were defined as successful or non-successful, as detailed above. \%EBWL was calculated in accordance with previous reports; [(pre-operative BMI - follow-up BMI)/(pre-operative BMI - Ideal Body Weight $(\mathrm{IBW}))] \times 100$. Ideal body weight was based on a BMI of $25 \mathrm{~kg} / \mathrm{m}^{2}[13,15,22]$.

\section{Statistical analysis}

Given the lack of information on skin signs in postbariatric patients, we based our sample size on the error around potential skin condition prevalence estimates of approximately $25 \%$ in post-bariatric patients. Enrolling 72 patients would allow estimation of the prevalence with an error of approximately $+/-10 \%$.

Statistical analysis was conducted using Stata 15.1 (Statacorp, College Station, TX, USA). Patients demographics and bariatric surgery data were described as mean (standard deviation [SD]) for continuous variables and $\mathrm{N}$ (\%) for categorical variables. The prevalence of skin signs and diseases was determined based on the presence or absence and described as $\mathrm{N}$ (\%), and the odds ratios (OR) of each sign in those with successful versus non-successful surgery was calculated using logistic regression. Where we found evidence of a 
significantly increased or decreased odds in those with successful surgery, we adjusted these for age, sex, and underlying diseases and finally reported these adjusted odds ratio (aOR), 95\% confident interval $(95 \% \mathrm{CI})$, and $p$-values. Changes in laboratory results was compared between baseline and a more than 6-month post bariatric surgery using paired-t test and reported as mean difference $(95 \% \mathrm{CI})$ both within and between weight-loss groups. The comparison of the percentage change of the lab results between successful and non-successful group were compared using an independent-t test.

\section{Results}

Seventy patients completed the study. The mean age was 41(9.60) years. A female predominance was observed with $46(65.7 \%)$ females and $24(34.3 \%)$ males. There were $46(65.7 \%)$ patients who attained successful weight loss and 24 (34.3\%) with non-successful weight loss. Baseline demographic data of the patients are shown in
Table 1. No statistically significant differences were observed between these 2 groups.

The presence of the skin manifestations in the two groups are shown in Table 2. Patients in the successful weight loss group demonstrated a statistically significantly lower prevalence of AN on the neck, axillae and inguinal area, KP and pebble fingers, compared to the non-successful counterparts. However, the higher prevalence of alopecia was observed. The number of other skin manifestations did not differ between the groups. After an adjustment for age, sex, and underlying diseases, $\mathrm{KP}$ (adjusted $\mathrm{OR}=0.21,95 \% \mathrm{CI}$ 0.06-0.74, $p=$ 0.015 ) and pebble fingers (adjusted $\mathrm{OR}=0.09,95 \% \mathrm{CI}$ $0.01-0.89, p=0.039$ ) remained statistically significant. Some of the skin manifestations are shown in Fig. 1.

There were $41(58.6 \%)$ patients with alopecia in this present study; 31 from the successful weight loss group and 10 from the non-successful. All of the cases were non-scarring alopecia. The diagnosis of telogen

Table 1 Demographic data of seventy post-bariatric surgery patients; overall and according to weight loss status

\begin{tabular}{|c|c|c|c|}
\hline & Total patients $(N=70)$ & $\begin{array}{l}\text { Non-successful weight loss patients } \\
(N=24,34.3 \%)\end{array}$ & $\begin{array}{l}\text { Successful weight loss patients } \\
(N=46,65.7 \%)\end{array}$ \\
\hline Mean age (SD) & $41(9.6)$ & $40(8.7)$ & $42(10)$ \\
\hline \multicolumn{4}{|l|}{ Sex } \\
\hline Male (\%) & $24(34.3 \%)$ & $11(45.8 \%)$ & $13(28.3 \%)$ \\
\hline Female (\%) & $46(65.7 \%)$ & $13(54.2 \%)$ & $33(71.7 \%)$ \\
\hline \multicolumn{4}{|l|}{ Bariatric surgery } \\
\hline RYGB $^{\mathrm{a}}$ & $48(68.6 \%)$ & $17(70.8 \%)$ & $31(67.4 \%)$ \\
\hline$S G^{a}$ & $22(31.4 \%)$ & $7(29.2 \%)$ & $15(32.6 \%)$ \\
\hline Mean (SD) months after surgery & $14.5(20)$ & $9.98(14.8)$ & $18(20.8)$ \\
\hline Mean (SD) preoperative weight & $131.38(29.85)$ & $137.22(28.82)$ & $128.33(30.24)$ \\
\hline Mean (SD) preoperative BMI & $43.38(9.68)$ & $50.17(9.54)$ & $47.44(9.73)$ \\
\hline Mean (SD) current weight & $94.83(23.9)$ & $114.7(24.88)$ & $84.47(15.46)$ \\
\hline Mean (SD) current BMI ${ }^{a}$ & $34.9(8.14)$ & $42(8.43)$ & $31.3(5.03)$ \\
\hline Mean (SD) total weight reduction percentage & $27.31(27.37)$ & $16.2(6.95)$ & $33.11(7.81)$ \\
\hline Mean (SD) EBWL ${ }^{a}$ percentage & $60.7(26.2)$ & $32.9(13)$ & $75.2(18.4)$ \\
\hline \multicolumn{4}{|l|}{ Diet modification } \\
\hline Yes (\%) & 59 (84.3\%) & $21(87.5 \%)$ & 38 (82.6\%) \\
\hline No (\%) & $11(15.7 \%)$ & $3(12.5 \%)$ & $8(17.4 \%)$ \\
\hline \multicolumn{4}{|l|}{ Underlying diseases } \\
\hline Hypertension, n (\%) & $42(60 \%)$ & 15 (62.5\%) & $27(58.7 \%)$ \\
\hline Dyslipidemia, n (\%) & $38(54.3 \%)$ & $16(66.7 \%)$ & $22(47.8 \%)$ \\
\hline Diabetes, n (\%) & 37 (52.9\%) & 15 (62.5\%) & $22(47.8 \%)$ \\
\hline PCOS ${ }^{a}, n(\%)$ & $19(27.1 \%)$ & $5(20.8 \%)$ & $14(30.4 \%)$ \\
\hline Others $^{\mathrm{b}}, \mathrm{n}(\%)$ & $100(142.9 \%)$ & 37 (154.7\%) & $74(158.7 \%)$ \\
\hline
\end{tabular}

${ }^{\mathrm{a} B M I}$ body mass index, EBWL percentage excess body weight loss percentage, calculated by [(pre-operative BMI - follow-up BMI)/ (pre-operative BMI - Ideal Body Weight (IBW))] $\times 100$. Ideal body weight was based on a BMI of $25 \mathrm{~kg} / \mathrm{m}^{2}, R Y G B$ Roux-en-Y gastric bypass, $P C O S$ polycystic ovarian syndrome, $S G$ sleeve gastrectomy; $(\mathrm{kg} / \mathrm{m} 2)$

${ }^{b}$ Others underlying diseases are referred to coronary artery diseases, obstructive sleep apnea (OSA), non-alcoholic steatohepatitis (NASH)/non-alcoholic fatty liver disease (NAFLD), kidney disease, inflammatory diseases, hypothyroidism, malignancy, hyperuricemia 
Table 2 Logistic regression results showing odds and adjusted* odds ratios of skin manifestations in patients who had successful versus non-successful weight loss post bariatric surgery

\begin{tabular}{|c|c|c|c|c|c|c|}
\hline \multirow[b]{2}{*}{ Skin manifestations } & \multirow[b]{2}{*}{$\begin{array}{l}\text { Non-successful weight loss } \\
\text { patients }(N=24)\end{array}$} & \multirow[b]{2}{*}{$\begin{array}{l}\text { Successful weight loss } \\
\text { patients }(N=46)\end{array}$} & \multicolumn{2}{|l|}{ Univariate } & \multicolumn{2}{|l|}{ Adjusted } \\
\hline & & & $\begin{array}{l}\mathrm{OR} \\
(95 \% \mathrm{Cl})\end{array}$ & $\begin{array}{l}p- \\
\text { value* }^{*}\end{array}$ & $\begin{array}{l}\text { Adjusted OR } \\
(95 \% \mathrm{Cl})^{\mathrm{a}}\end{array}$ & $\begin{array}{l}\text { Adjusted } p \text { - } \\
\text { value* }\end{array}$ \\
\hline \multicolumn{7}{|l|}{ Hair } \\
\hline Alopecia (\%) & $10(41.67 \%)$ & $31(67.39 \%)$ & $\begin{array}{l}2.89(1.04 \\
8.02)\end{array}$ & $0.04^{*}$ & $2.75(0.88,8.57)$ & 0.08 \\
\hline \multicolumn{7}{|l|}{ Skin } \\
\hline Psoriasis (\%) & $0(0 \%)$ & $2(4.35 \%)$ & $1(-)$ & - & - & - \\
\hline Diagonal earlobe creases (\%) & $1(4.17 \%)$ & $1(2.17 \%)$ & $\begin{array}{l}0.51(0.03 \\
8.55)\end{array}$ & 0.64 & - & - \\
\hline Acanthosis nigricans (\%) & $15(62.5 \%)$ & $19(41.3 \%)$ & $\begin{array}{l}0.42(0.15 \\
1.16)\end{array}$ & 0.10 & - & - \\
\hline AN-neck (\%) & $15(62.5 \%)$ & $17(36.96 \%)$ & $\begin{array}{l}0.35(0.13 \\
0.98)\end{array}$ & $0.045^{*}$ & $0.33(0.09,1.17)$ & 0.09 \\
\hline AN-axillae (\%) & $11(45.83 \%)$ & $9(19.57 \%)$ & $\begin{array}{l}0.29(0.1 \\
0.85)\end{array}$ & $0.03^{*}$ & $0.37(0.11,1.27)$ & 0.11 \\
\hline AN-antecubital fossa (\%) & $2(8.33 \%)$ & $2(4.35 \%)$ & $\begin{array}{l}0.5(0.07 \\
3.79)\end{array}$ & 0.50 & - & - \\
\hline AN-inguinal areas (\%) & $6(25 \%)$ & $3(6.52 \%)$ & $\begin{array}{l}0.21(0.05 \\
0.93)\end{array}$ & $0.04^{*}$ & $0.21(0.04,1.21)$ & 0.08 \\
\hline AN-inframammary areas (\%) & $1(4.17 \%)$ & $0(0 \%)$ & $1(-)$ & - & - & - \\
\hline Acrochordons/skin tags (\%) & $11(45.83 \%)$ & $24(52.17 \%)$ & $\begin{array}{l}1.29(0.48 \\
3.47)\end{array}$ & 0.62 & - & - \\
\hline $\begin{array}{l}\text { Acrochordons/skin tags -neck } \\
(\%)\end{array}$ & $8(33.33 \%)$ & $22(47.83 \%)$ & $\begin{array}{l}1.83(0.66 \\
5.12)\end{array}$ & 0.25 & - & - \\
\hline $\begin{array}{l}\text { Acrochordons/skin tags-axillae } \\
\text { (\%) }\end{array}$ & $3(12.5 \%)$ & $9(19.57 \%)$ & $\begin{array}{l}1.7(0.41 \\
6.99)\end{array}$ & 0.46 & & \\
\hline $\begin{array}{l}\text { Acrochordons/skin tags- } \\
\text { inguinal areas (\%) }\end{array}$ & $0(0 \%)$ & $2(4.35 \%)$ & - & - & - & - \\
\hline $\begin{array}{l}\text { Acrochordons/skin tags-eyelid } \\
(\%)\end{array}$ & $1(4.17 \%)$ & $1(2.17 \%)$ & $\begin{array}{l}0.51(0.03 \\
8.55)\end{array}$ & 0.64 & - & - \\
\hline $\begin{array}{l}\text { Acrochordons/skin tags-trunk } \\
\text { (\%) }\end{array}$ & $5(20.83 \%)$ & $6(13.04 \%)$ & $\begin{array}{l}0.57(0.15 \\
2.10)\end{array}$ & 0.40 & - & - \\
\hline $\begin{array}{l}\text { Acrochordons/skin tags- } \\
\text { inframammary areas (\%) }\end{array}$ & $1(4.17 \%)$ & $0(0 \%)$ & $1(-)$ & - & - & - \\
\hline KP (\%) & $14(58.33 \%)$ & $12(26.09 \%)$ & $\begin{array}{l}0.25(0.09 \\
0.72)\end{array}$ & $0.01^{*}$ & $0.21(0.06,0.74)$ & $0.02^{*}$ \\
\hline Pebble fingers (\%) & $5(20.83 \%)$ & $1(2.17 \%)$ & $\begin{array}{l}0.08(0.01 \\
0.77)\end{array}$ & $0.03^{*}$ & $0.09(0.01,0.89)$ & $0.04^{*}$ \\
\hline Striae distensae (\%) & $16(66.67 \%)$ & $27(58.7 \%)$ & $\begin{array}{l}0.71(0.25 \\
1.99)\end{array}$ & 0.52 & - & - \\
\hline Folliculitis (\%) & $2(8.33 \%)$ & $2(4.35 \%)$ & $\begin{array}{l}0.5(0.07 \\
3.8)\end{array}$ & 0.50 & - & - \\
\hline Intertrigo (\%) & $7(29.17 \%)$ & $12(26.09 \%)$ & $\begin{array}{l}0.86(0.29 \\
2.57)\end{array}$ & 0.78 & - & - \\
\hline $\begin{array}{l}\text { Chronic venous disease } \\
\text { manifestations (\%) }\end{array}$ & $9(37.5 \%)$ & $11(23.91 \%)$ & $\begin{array}{l}0.52(0.18 \\
1.52)\end{array}$ & 0.24 & - & - \\
\hline Plantar hyperkeratosis (\%) & 19 (79.17\%) & $27(58.70 \%)$ & $\begin{array}{l}0.37(0.12 \\
1.18)\end{array}$ & 0.09 & - & - \\
\hline
\end{tabular}

$A N$ acanthosis nigricans, KP keratosis pilaris

${ }^{*} p<0.05$

${ }^{a}$ Adjusted for age, sex, and underlying diseases (i.e. hypertension, dyslipidemia, diabetes mellitus, and polycystic ovarian syndrome) 


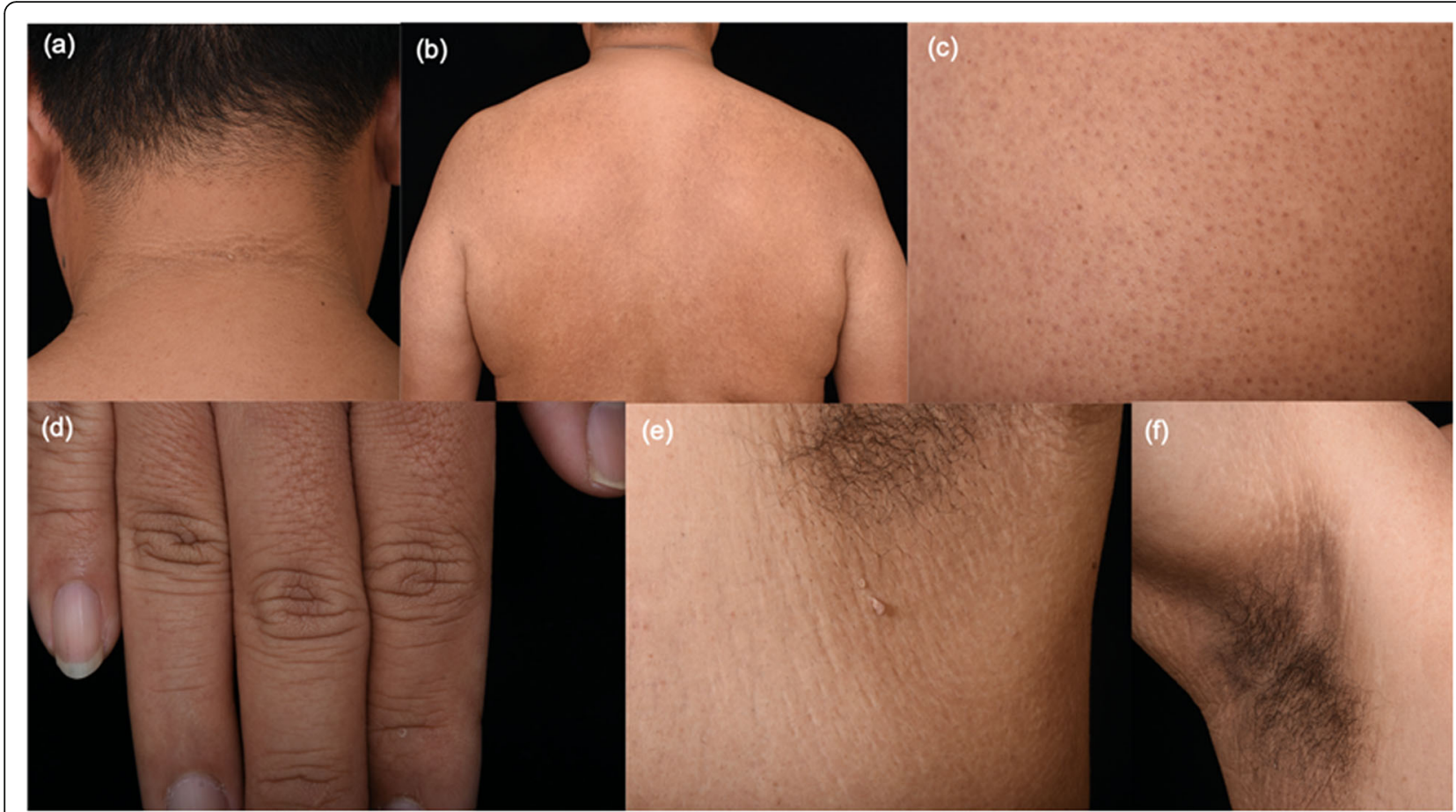

Fig. 1 Acanthosis nigricans and acrochordon on the neck (a); keratosis pilaris on the back (b); keratosis pilaris on the arm (c); pebble fingers (d); intertrigo and acrochordons on left axilla (e); intertrigo and striae on right axilla (f) in a patient with 48.9\%EBWL

effluvium (diffuse and excessive shedding more than 70100 hairs per day and clinical examination showed diffuse hair thinning) was made in 14 patients while a pattern hair loss compatible with androgenetic alopecia was found in 34 patients. Seven patients have both diffuse and pattern hair loss. Hair pulling test was found positive ( $\geq 3$ hairs) in 3 patients. In the diffuse hair loss group, the mean onset of hair loss was $3.07 \pm 1.2$ months after the surgery.

In addition to the classic skin manifestations reported in the patients with obesity, the following mucocutaneous signs were observed in our patients; pigmented fungiform papillae $(N=1)$, lichen amyloidosis on the extremities $(N=3$ patients, 2 in the successful weight loss group and 1 in the other), hypertrophic scar $(N=1)$, keloid $(N=1)$, en coup de sabre-type morphea $(N=1)$, chronic paronychia $(N=1)$, callus $(N=1)$, and fibrous papules of the nose $(N=1)$. However, the prevalence of all of these signs was low, and showed no differences between the two groups.

The within-group laboratory results comparing preand post-surgery values are shown in Table 3. Both successful and non-successful weight loss groups showed statistically significant decreases of white blood cells (WBC) $(p<0.001$ and 0.016 in the successful and nonsuccessful groups, respectively), as well as fasting plasma glucose (FPG) $(p=0.005$ and 0.01$), \mathrm{HbA1C}(p=0.003$ and $<0.001)$ and triglyceride (TG) $(p=0.005$ and 0.034$)$.
An increase of high-density lipoproteins (HDL) was also observed in both groups ( $p=0.001$ and 0.034$)$. Additionally, only the successful weight loss group exhibited a statistically significant decreases of aspartate aminotransferase (AST) $(p=0.043)$, alanine aminotransferase (ALT) $(p=0.003)$, vitamin $\mathrm{B} 12(p=0.048)$, and total iron binding capacity (TIBC) $(p=0.001)$ and an increase in total cholesterol (TC) $(p=0.037)$ after the surgery.

When compared between the successful vs. nonsuccessful weight loss groups (between group analysis, Table 3, last column), the successful weight loss group had a significantly larger decreases in vitamin B12 and TIBC ( $p=0.01$ and 0.029 , respectively). A significantly greater increase in ferritin was detected in the successful weight loss group $(p=0.023)$.

\section{Discussions}

From this present study, we are able to demonstrate that lower numbers of patients in the successful weight loss group were affected by certain skin signs, namely KP and pebble finger.

Moreover, bariatric surgery provided improvements in metabolic profiles. There were decreases of FPG, HbA1C and TG, and increase in HDL in both groups. Interestingly, only the successful weight loss group exhibited significant decreases of AST and ALT. However, lower level of vitamin B12 and TIBC and an increase in ferritin were detected in the successful group. 
Table 3 Laboratory changes from baseline to > six months, categorized according to weight loss status

\begin{tabular}{|c|c|c|c|c|c|c|c|}
\hline \multirow[t]{2}{*}{ Parameter } & \multicolumn{3}{|c|}{ Non-successful weight loss patients } & \multicolumn{3}{|c|}{ Successful weight loss patients } & \multirow[b]{2}{*}{$\begin{array}{l}P . \text { value } \\
\text { (mean } \\
\text { changes } \\
\text { from } \\
\text { baseline } \\
\text { to }>6 \\
\text { months } \\
\text { between } \\
\text { weight } \\
\text { loss } \\
\text { groups) }\end{array}$} \\
\hline & $\bar{n}$ & $\begin{array}{l}\text { Mean changes from baseline to }>6 \text { months } \\
(95 \% \mathrm{Cl})\end{array}$ & $\begin{array}{l}p . \\
\text { value }\end{array}$ & $\bar{n}$ & $\begin{array}{l}\text { Mean changes from baseline to }>6 \\
\text { months }(95 \% \mathrm{Cl})\end{array}$ & $\begin{array}{l}p . \\
\text { value }\end{array}$ & \\
\hline $\mathrm{Hb}$ & 14 & $-0.22(-0.83,0.38)$ & 0.44 & 33 & $-0.35(-0.71,0.004)$ & 0.05 & 0.69 \\
\hline Plt $\left(\times 10^{3}\right)$ & 14 & $-19.29(-41.58,3.006)$ & 0.08 & 33 & $-35.12(-51.61,-18.63)$ & $\begin{array}{l}< \\
0.001^{*}\end{array}$ & 0.27 \\
\hline $\begin{array}{l}\text { WBC }(\times \\
\left.10^{3}\right)\end{array}$ & 14 & $-1.5(-2.67,-0.33)$ & $0.02^{*}$ & 33 & $-2.88(-3.68,-2.09)$ & $\begin{array}{l}< \\
0.001^{*}\end{array}$ & 0.05 \\
\hline FPG & 13 & $-18.08(-30.9,-5.25)$ & $0.01^{*}$ & 29 & $-7.76(-12.97,-2.55)$ & $0.005^{*}$ & 0.07 \\
\hline $\mathrm{HbA} 1 \mathrm{C}$ & 12 & $-0.875(-1.17,-0.58)$ & $\begin{array}{l}< \\
0.001^{*}\end{array}$ & 22 & $-1.02(-1.66,-0.39)$ & $0.003^{*}$ & 0.73 \\
\hline $\mathrm{Cr}$ & 13 & $0.04(-0.07,0.15)$ & 0.44 & 33 & $0.25(-0.40,0.90)$ & 0.44 & 0.68 \\
\hline AST & 14 & $-5.5(-15.46,4,46)$ & 0.25 & 33 & $-7.24(-14.25,-0.23)$ & $0.04^{*}$ & 0.78 \\
\hline ALT & 14 & $-12.64(-29.75,4.47)$ & 0.13 & 33 & $-13.39(-21.91,-4.88)$ & $0.003^{*}$ & 0.93 \\
\hline ALP & 5 & $11.8(-9.82,33.42)$ & 0.20 & 12 & $6.42(-6.35,19.19)$ & 0.29 & 0.61 \\
\hline TC & 9 & $-2.89(-49.40,43.62)$ & 0.89 & 17 & $25(1.71,48.28)$ & $0.04^{*}$ & 0.20 \\
\hline $\mathrm{HDL}$ & 9 & $8(0.77,15.23)$ & $0.03^{*}$ & 17 & $8.23(3.95,12.52)$ & $\begin{array}{l}< \\
0.001^{*}\end{array}$ & 0.95 \\
\hline TG & 9 & $-58.22(-110.6,-5.84)$ & $0.03^{*}$ & 17 & $-32.65(-54.10,-11.19)$ & $0.005^{*}$ & 0.25 \\
\hline LDL & 9 & $-4.89(-49.80,40.02)$ & 0.81 & 16 & $11.13(-10.52,32.77)$ & 0.29 & 0.43 \\
\hline $\begin{array}{l}\text { Vitamin } \\
\text { B12 }\end{array}$ & 4 & $206.48(-131.01,543.96)$ & 0.15 & 12 & $-113.33(-225.72,-0.93)$ & $0.048^{*}$ & $0.01^{*}$ \\
\hline Folate & 4 & $0.52(-5.38,6.41)$ & 0.80 & 12 & $-2.17(-5.19,0.86)$ & 0.14 & 0.33 \\
\hline Ferritin & 3 & $-177.3(-576.75,222.15)$ & 0.20 & 11 & $1.16(-59.06,61.39)$ & 0.97 & $0.02^{*}$ \\
\hline Iron & 2 & $19.5(-215.56,254.56)$ & 0.48 & 5 & $-26.2(-65.32,12.92)$ & 0.14 & 0.13 \\
\hline $\mathrm{TIBC}$ & 1 & -22 & - & 4 & $-95.25(-121.79,-68.71)$ & $0.001^{*}$ & $0.03^{*}$ \\
\hline Vitamin D & 8 & $10.74(-3.13,24.62)$ & 0.11 & 15 & $25.67(-11.03,62.37)$ & 0.16 & 0.54 \\
\hline
\end{tabular}

$\mathrm{Hb}$ hemoglobin $(\mathrm{g} / \mathrm{dL})$, Plt platelet $\left(\mathrm{x} 10^{3} \mathrm{~g} / \mathrm{dL}\right), W B C$ White blood cells $\left(\mathrm{x} 10^{3} \mathrm{~g} / \mathrm{dL}\right), F P G$ fasting plasma glucose, HbA1C hemoglobinA1C, Cr creatinine, AST Aspartate aminotransferase, $A L T$ Alanine aminotransferase, $A L P$ alkaline phosphatase, $T C$ total cholesterol, $H D L$ high-density lipoprotein, $T G$ triglyceride, $L D L$ low-density lipoprotein, $T I B C$ total iron binding capacity ${ }^{*} p<0.05$

Improvements of AN, acrochordons, intertrigo, hidradenitis suppurativa, psoriasis and necrobiosis lipoidica have been reported after bariatric surgery [18]. The result of our study also demonstrates that in patients who achieved successful weight loss, the prevalence of KP and pebble finger is lower. The correlation of $\mathrm{AN}, \mathrm{KP}$ and pebble fingers with insulin resistance and hyperinsulinemia is well established [3, 5, 7]. Diet control that leads to weight reduction can improve insulin resistance status and lessen AN severity [23]. We speculate that the lower number of KP and pebble fingers in the successful group might result from a greater improvement of insulin resistance after weight reduction in this group.
Alopecia can be associated with nutritional deficiency and an abrupt and massive weight loss [17, 24]. A oneyear prospective study showed that $41 \%$ of post-bariatric surgery women developed alopecia related to iron and zinc deficiency, and that zinc supplementation could improve the condition [24]. A significantly higher prevalence of alopecia was observed in successful weight loss patients in our study. Though after adjustment with the patients' factors, it became statistically non-significant, the OR and upper $95 \% \mathrm{CI}$ were still approximately the same in the adjusted and the unadjusted models, indicating a higher risk of alopecia even after adjustment for patient factors. All patients included in this study were routinely prescribed with nutritional supplements after 
the surgery (multivitamins1-2 tablets, calcium 1000$2000 \mathrm{mg}$ per day, vitamin D 40,000 units per week and B12 1000 mcg injection every 3 months).

Improvements in laboratory metabolic profiles are well demonstrated in our study. A systematic review and meta-regression demonstrated that a reduction of BMI by $1.6 \mathrm{~kg} / \mathrm{m}^{2}$ in children can decrease TG by $16 \mathrm{mg} / \mathrm{dL}$ and increase HDL by $1.7 \mathrm{mg} / \mathrm{dL}$. On the other hand, other blood profiles, i.e. TC, low-density lipoproteins (LDL), AST, ALT, gamma-glutamyl transferase (GGT), FPG, and HbA1c, are not significantly correlated with degree of weight loss [25-28]. In addition, a long-term study in adult population has shown that weight loss after bariatric surgery can lead to remission and prevention of type 2 DM, dyslipidemia and hypertension [28]. These are consistent with our data. In this present study, TG and HDL-c were shown to improve significantly in post-bariatric surgery patients regardless of their successful weight loss status. Moreover, we were also able to demonstrate significant improvements in AST and ALT profiles only in the individuals achieving successful weight loss. These data suggest that achieving successful weight control might additionally, improve the liver condition.

Nutritional deficiency is a well-established complication of bariatric surgery $[17,20]$ with vitamin B12 deficiency being the most common [20]. Clinical skin signs associated with vitamin B12 deficiency are cheilitis, glossitis, hair depigmentation, and diffuse or symmetric hyperpigmentation [20]. In this study, we did not find any skin signs of B12 deficiency in our patients. Moreover, none of the patients showed levels below the normal cut-off point $(<148 \mathrm{pmol} / \mathrm{l})$. However, statistically significantly decreased levels of vitamin B12 in the successful weight loss group was observed. This emphasizes that blood profiles might be a better early predictor to evaluate nutritional status, compared to the skin signs or deficiency determined by cut off points alone. Interestingly, an increase in ferritin was detected in the successful group. We speculate that this might be due to a better compliance in taking the supplements of the patients in the group. Further studies are needed to confirm this finding.

The limitations of our study include its cross-sectional nature. The skin examination is conducted only once. Therefore, we cannot evaluate skin improvements from the baseline, only the prevalence at the point of the examination can be obtained. Certain skin signs have been reported to get better after weight reduction. From our study, we were able to identify that there were less patients with KP and pebble finger in the successful group. These results were in keeping with the fact that weight reduction may improve the adverse skin changes. However, long-term prospective studies are needed to demonstrate changes through the course and at later times after the surgery.

\section{Conclusions}

Weight loss after bariatric surgery provides an improvement in metabolic profiles. Furthermore, less patients with successful weight loss had certain skin findings. Importantly, nutritional supplement is necessary for post bariatric surgery individuals, since some skin signs might be late presentations indicating a greater degree of severity.

\begin{abstract}
Abbreviations
BaS: Bariatric surgery; EBWL: Excessive body weight loss; KP: Keratosis pilaris; AST: Aspartate aminotransferase; ALT: Alanine aminotransferase; BMI: Body mass index; AN: Acanthosis nigricans; DM: Diabetes mellitus; FPG: Fasting plasma; HbA1C: Hemoglobin A1C; TG: Triglyceride; HDL: High-density lipoproteins; TIBC: Total iron binding capacity; LDL: Low-density lipoproteins; GGT: Gamma-glutamyl transferase
\end{abstract}

\section{Acknowledgements}

This study was funded by Ratchadapisek Somphot Endowment Fund, RA61/ 025, Faculty of Medicine, Chulalongkorn University, Bangkok Thailand. The authors sincerely thank Dr. Sarinyarapat Buranakiti and Skin and Allergy Research Unit, Chulalongkorn University for their support.

\section{Authors' contributions}

PR: Conceptualization, Methodology, Writing- Reviewing and Editing, Funding acquisition. Yl; Investigation, Formal analysis, Writing- Original draft preparation. WD: Investigation. NT: Investigation. SU: Resources. PB: Methodology, Writing - Review \& Editing. CK: Methodology, Formal analysis, Writing - Review \& Editing. SJK: Formal analysis, Writing - Review \& Editing. PA: Conceptualization, Writing - Review \& Editing. All authors have read and approved the manuscript.

\section{Funding}

This research received grant from a Ratchadapisek Somphot Endowment Fund, RA61/025, Faculty of Medicine, Chulalongkorn University. The funding body had no role in the design of the study, the collection, analysis and interpretation of data and in writing the manuscript.

\section{Availability of data and materials}

The data that support the findings of this study are available from the corresponding author upon reasonable request.

\section{Ethics approval and consent to participate}

Research was in accordance with Declaration of Helsinki. The study was approved by Institutional Review Board, Faculty of Medicine, Chulalongkorn University, the approval number 633/60. The trial was registered with Thai Clinical Trials Registry, TCTR number 20171003002. Written informed consent was obtained from all participants after full explanation of the purpose and nature of all procedures used.

\section{Consent for publication}

The participants gave written consent for their personal or clinical details along with any identifying images to be published in this study.

\section{Competing interests}

$\mathrm{YI}, \mathrm{WD}, \mathrm{NT}, \mathrm{SU}, \mathrm{PB}, \mathrm{CK}, \mathrm{SK}, \mathrm{PA}$, and PR have no competing interests.

\section{Author details}

'Division of Dermatology, Department of Medicine, Faculty of Medicine, Skin and Allergy Research Unit, Chulalongkorn University, 1873 Rama IV Road, Pathumwan, Bangkok 10330, Thailand. ${ }^{2}$ Department of Surgery, Faculty of Medicine, Chulalongkorn University, Bangkok, Thailand. ${ }^{3}$ Division of Endocrinology and Metabolism, Faculty of Medicine, Chulalongkorn University, Bangkok, Thailand. ${ }^{4}$ Center for Excellence in Biostatistics, Faculty of Medicine, Chulalongkorn University, Bangkok, Thailand. 
Received: 18 May 2020 Accepted: 1 December 2020

Published online: 09 December 2020

\section{References}

1. Ng M, Fleming T, Robinson M, Thomson B, Graetz N, Margono C, et al. Global, regional, and national prevalence of overweight and obesity in children and adults during 1980-2013: a systematic analysis for the global burden of disease study 2013. Lancet. 2014;384:766-81.

2. Hidalgo LG. Dermatological complications of obesity. Am J Clin Dermatol. 2002;3:497-506

3. Yosipovitch G, DeVore A, Dawn A. Obesity and the skin: skin physiology and skin manifestations of obesity. J Am Acad Dermatol. 2007;56:901-16 quiz 17-20.

4. Hirt PA, Castillo DE, Yosipovitch G, Keri JE. Skin changes in the obese patient. J Am Acad Dermatol. 2019;81:1037-57.

5. Wenczl E. Skin manifestations, treatment and rehabilitation in overweight and obesity. Orv Hetil. 2009;150:1731-8.

6. Gallagher SM. Morbid obesity: a chronic disease with an impact on wounds and related problems. Ostomy Wound Manage. 1997;43:18-24 6-7.

7. Geffner ME, Golde DW. Selective insulin action on skin, ovary, and heart in insulin-resistant states. Diabetes Care. 1988;11:500-5.

8. Tabor CA, Parlette EC. Cutaneous manifestations of diabetes. Signs of poor glycemic control or new-onset disease. Postgrad Med. 2006;119:38-44

9. Hud JA Jr, Cohen JB, Wagner JM, Cruz PD Jr. Prevalence and significance of acanthosis nigricans in an adult obese population. Arch Dermatol. 1992;128: 941-4.

10. Garcia-Hidalgo L, Orozco-Topete R, Gonzalez-Barranco J, Villa AR, Dalman JJ, Ortiz-Pedroza G. Dermatoses in 156 obese adults. Obes Res. 1999;7:299-302.

11. Shipman AR, Millington GW. Obesity and the skin. Br J Dermatol. 2011;165: 743-50.

12. Garvey WT, Mechanick JI, Brett EM, Garber AJ, Hurley DL, Jastreboff AM, et al. American association of clinical endocrinologists and American College of Endocrinology comprehensive clinical practice guidelines for medical care of patients with obesity. Endocr Pract. 2016;22(Suppl 3):1-203.

13. Robinson AH, Adler S, Stevens HB, Darcy AM, Morton JM, Safer DL. What variables are associated with successful weight loss outcomes for bariatric surgery after 1 year? Surg Obes Relat Dis. 2014;10:697-704.

14. Elder KA, Wolfe BM. Bariatric surgery: a review of procedures and outcomes. Gastroenterology. 2007:132:2253-71.

15. Buchwald H, Avidor Y, Braunwald E, Jensen MD, Pories W, Fahrbach K, et al. Bariatric surgery: a systematic review and meta-analysis. JAMA. 2004;292: 1724-37.

16. Egeberg A, Sorensen JA, Gislason GH, Knop FK, Skov L. Incidence and prognosis of psoriasis and psoriatic arthritis in patients undergoing bariatric surgery. JAMA Surg. 2017;152:344-9.

17. Rosen J, Darwin E, Tuchayi SM, Garibyan L, Yosipovitch G. Skin changes and manifestations associated with the treatment of obesity. J Am Acad Dermatol. 2019:81:1059-69.

18. Wollina U, Dressler M, Lohmann T. Bariatric surgery - a dermatologic perspective. J Eur Acad Dermatol Venereol. 2015;29:835-41.

19. Halawi A, Abiad F, Abbas O. Bariatric surgery and its effects on the skin and skin diseases. Obes Surg. 2013;23:408-13.

20. Manzoni AP, Weber MB. Skin changes after bariatric surgery. An Bras Dermatol. 2015:90:157-66.

21. Aldaqal SM, Makhdoum AM, Turki AM, Awan BA, Samargandi OA, Jamjom $H$. Post-bariatric surgery satisfaction and body-contouring consideration after massive weight loss. N Am J Med Sci. 2013;5:301-5.

22. Steinbeisser M, McCracken J, Kharbutli B. Laparoscopic sleeve Gastrectomy: preoperative weight loss and other factors as predictors of postoperative success. Obes Surg. 2017;27:1508-13.

23. Kuroki R, Sadamoto $Y$, Imamura M, Abe $Y$, Higuchi $K$, Kato $K$, et al. Acanthosis nigricans with severe obesity, insulin resistance and hypothyroidism: improvement by diet control. Dermatology. 1999;198:164-6.

24. Ruiz-Tovar J, Oller I, Llavero C, Zubiaga L, Diez M, Arroyo A, et al. Hair loss in females after sleeve gastrectomy: predictive value of serum zinc and iron levels. Am Surg. 2014;80:466-71.

25. Rajjo T, Almasri J, Al Nofal A, Farah W, Alsawas M, Ahmed AT, et al. The Association of Weight Loss and Cardiometabolic Outcomes in obese children: systematic review and meta-regression. J Clin Endocrinol Metab. 2017;102:758-62.
26. Sumithran P, Prendergast LA, Haywood CJ, Houlihan CA, Proietto J. Review of 3-year outcomes of a very-low-energy diet-based outpatient obesity treatment programme. Clin Obes. 2016;6:101-7.

27. Xu S, Xue Y. Pediatric obesity: causes, symptoms, prevention and treatment. Exp Ther Med. 2016;11:15-20.

28. Adams TD, Davidson LE, Litwin SE, Kim J, Kolotkin RL, Nanjee MN, et al. Weight and metabolic outcomes 12 years after gastric bypass. N Engl J Med. 2017;377:1143-55.

\section{Publisher's Note}

Springer Nature remains neutral with regard to jurisdictional claims in published maps and institutional affiliations.

\section{Ready to submit your research? Choose BMC and benefit from:}

- fast, convenient online submission

- thorough peer review by experienced researchers in your field

- rapid publication on acceptance

- support for research data, including large and complex data types

- gold Open Access which fosters wider collaboration and increased citations

- maximum visibility for your research: over $100 \mathrm{M}$ website views per year

At BMC, research is always in progress.

Learn more biomedcentral.com/submissions 